\title{
Arquivos Brasileiros de Psiquiatria, Neurologia e Ciências Afins: uma fonte com muita história
}

\author{
Arquivos Brasileiros de Psiquiatria, Neurologia \\ e Ciências Afins: a source rich in history
}

\section{Cristiana Facchinetti}

Pesquisadora do Departamento de Pesquisa e professora do Programa de Pós-graduação em História das Ciências e da Saúde/Casa de Oswaldo Cruz (COC)/Fundação Oswaldo Cruz (Fiocruz) cfac@coc.fiocruz.br

\section{Priscila Cupello}

Bolsista de Iniciação Científica da Faperj/Fiocruz.

priscilacupello@hotmail.com

\section{Danielle Ferreira} Evangelista

Bolsista de Iniciação Científica da Faperj/Fiocruz.

danielefge@limao.com.br

Av. Brasil, 4036/sala 400

21040-361 - Rio de Janeiro - RJ Brasil

cfac@fiocruz.br
FACCHINETTI, Cristiana; CUPELLO, Priscila; EVANGELISTA, Danielle Ferreira. Arquivos Brasileiros de Psiquiatria, Neurologia e Ciências Afins: uma fonte com muita história. História, Ciências, Saúde - Manguinhos, Rio de Janeiro, v.17, supl.2, dez. 2010, p.527-535.

\section{Resumo}

Surgido em 1905, o Arquivos Brasileiros de Psiquiatria, Neurologia e Ciências Afins foi o primeiro periódico brasileiro especializado na área. Com o nome de Arquivos Brasileiros de Psiquiatria, Neurologia e Medicina Legal, tornou-se, em 1908, veículo de divulgação da Sociedade com o mesmo nome. A partir de 1919 foi publicado como Arquivos Brasileiros de Neuriatria e Psiquiatria. O periódico traz as propostas para a psiquiatria brasileira lideradas por Juliano Moreira, diretor do Hospício Nacional e da Assistência a Alienados do Distrito Federal. Por veicular trabalhos de profissionais do Hospício Nacional, é fonte fundamental para a investigação dos processos diagnósticos e das práticas clínicas e terapêuticas do período. Apresenta-se aqui uma seleção de artigos publicados na revista entre 1905 e 1930, ano da aposentadoria de Moreira.

Palavras-chave: psiquiatria; história; periódicos; Hospício Nacional; Brasil.

\section{Abstract}

Launched in 1905, the Arquivos Brasileiros de Psiquiatria, Neurologia e Ciências Afins was the first Brazilian periodical specialized in psychiatry, neurology, and related sciences. In 1908, under the new name of Arquivos Brasileiros de Psiquiatria, Neurologia e Medicina Legal, it became the journal of the Society of Psychiatry, Neurology, and Forensic Medicine. Starting in 1919, it was published under the title Arquivos Brasileiros de Neuriatria e Psiquiatria. The periodical presents proposals put forward for this field in Brazil, under the leadership of Juliano Moreira, director of both the National Asylum and of Federal District Assistance for the Insane (Assistência a Alienados do Distrito Federal). Because the journal published articles by healthcare providers from the National Asylum, it is a vital source for researchers of the era's diagnostic processes and clinical and therapeutic practices. This selection of texts was published in its pages between 1905 and 1930, the year Moreira retired.

Keywords: psychiatry; history; periodicals; Hospício Nacional de Alienados; Brazil. 
A revista Arquivos Brasileiros de Psiquiatria, Neurologia e Ciências Afins foi criada em 1905 pelos psiquiatras Juliano Moreira ${ }^{1}$ e Afrânio Peixoto². Sua proposta era "registrar as contribuições nacionais" e "estimular os especialistas nacionais ao estudo acurado de seus doentes" (Nota editorial, 1905, p.7). Na avaliação de seus editores, a primeira revista do país especializada no campo da medicina mental "não só elevou o bom nome do Brasil perante os mais notáveis centros científicos do estrangeiro, como ainda concorreu para que recebêssemos para a biblioteca médica do estabelecimento inúmeras publicações de inestimável valor" (p.7). Ainda na sua opinião, as publicações brasileiras desapareciam precocemente "mais por falta de quem as escreva, que de quem as leia" (p.7); sendo assim, demandavam a colaboração maciça dos psiquiatras brasileiros para que a revista não corresse o risco desaparecer também.

Ela veiculava basicamente artigos que tratavam da assistência a alienados no Brasil e no mundo, discutindo categorias diagnósticas diversas ou divulgando debates travados no campo médico-mental, fosse por representantes das diferentes escolas francesas ou italianas, ou pela nova escola kraepeliana, com direito a réplica e mesmo tréplica dos oponentes. Foi o que ocorreu, por exemplo, com Franco da Rocha ${ }^{3}$ (1905), de um lado, e Juliano Moreira e Afrânio Peixoto (1905a), de outro, a propósito da loucura maníaco-depressiva; entre Antonio Austregésilo4 (1905) e Moreira e Peixoto (1905a), a respeito da degeneração; ou na querela acerca da degeneração racial e do meio ambiente, que opôs Nina Rodrigues ${ }^{5} \mathrm{e}$ Moreira (1908). Assim, até a hegemonia do paradigma organicista na psiquiatria, entre os anos de 1920 e 1930, os Arquivos Brasileiros constituíram uma arena para o confronto entre diferentes escolas, contrapondo principalmente a psiquiatria alemã e o alienismo francês, tão assentado no país, contribuindo esses embates para divulgar conceitos e estratégias diagnósticas desses saberes.

Tal difusão se fazia também pela tradução de trabalhos de alguns dos principais autores da linha organicista, como a "Classificação das moléstias mentais do prof. Emil Kraepelin" (Moreira, Peixoto, 1905b), e pela composição de resenhas publicadas na seção Análises, que tratavam das obras do psiquiatra alemão e de outros médicos da mesma corrente. Finalmente, a publicação nos Arquivos Brasileiros das atas de reuniões da Sociedade de Psiquiatria, Neurologia e Medicina Legal reafirmava o objetivo de comprovar e difundir "os avanços científicos" no tratamento dos alienados, por meio da sua aproximação ao modelo kraepeliano (Sociedade Brasileira..., 1907).

A revista era produzida no interior do Hospício, no Pavilhão Seabra", pelos "enfermos tipógrafos, os quais, por esse meio, não só não esquecem sua profissão, como encontram no trabalho uma distração" (Brasil, 1912, p.62).

Desde sua criação até a saída de Juliano Moreira da direção do Hospício Nacional7 , em 1930, a revista teve seu nome mudado algumas vezes. A partir de 1908 passou a se chamar Arquivos Brasileiros de Psiquiatria, Neurologia e Medicina Legal, devido à criação, em 17 de novembro do ano anterior, da Sociedade de Psiquiatria, Neurologia e Medicina Legal. Os médicos responsáveis por tal iniciativa estavam convencidos de que "tão útil agrupamento" permitiria maior difusão, aos diferentes grupos médicos-mentais do país, desses ramos do conhecimento, assim como do tratamento de alienados no Hospício Nacional (Sociedade 
Brasileira..., 1907). Como órgão oficial da Sociedade, a revista inaugurou uma seção específica para veicular as atas de suas assembléias e reuniões e de seus congressos.

Em 1915 os dez anos de publicação de Arquivos foram comemorados com entusiasmo por seus fundadores e colaboradores. Em sua avaliação, a revista materializara um espaço reconhecido de publicação científica especializada, no "Brasil e no exterior". Apesar de o periódico não ter conquistado "a adesão de alguns especialistas nacionais", mostravam-se satisfeitos com os resultados, considerando que "dez anos de existência para uma revista de especialidade no Brasil é caso raro, senão único" (Nota editorial, 1915).

Para reafirmar o comprometimento com a neurologia e a medicina legal, os editores, a partir de 1915, puseram em evidência, nas capas da revista, as três áreas de conhecimento, com seus respectivos responsáveis: na psiquiatria, Juliano Moreira; na neurologia, Antônio Austregésilo; e na medicina legal, Afrânio Peixoto. A redação também foi dividida nessas áreas, sendo confiadas a antigos colaboradores: Henrique Roxo ${ }^{8}$, Fernandes Figueira ${ }^{9}$ e Ulysses Vianna ${ }^{10}$, pela psiquiatria; Faustino Esposel ${ }^{11}$, Moreira da Fonseca ${ }^{12}$ e Waldemar Schiller ${ }^{13}$, pela neurologia; Diógenes Sampaio ${ }^{14}$, Jacinto de Barros ${ }^{15}$ e Miguel Salles ${ }^{16}$, pela medicina legal (Nota editorial, 1915).

Inicialmente a revista era trimestral; de 1915 a 1919 foi bimestral; de 1920 a 1928 voltou a ser trimestral; e em 1929 tornou-se outra vez bimestral. Até pelo menos 1955 (última data encontrada pelos pesquisadores), o periódico manteve periodicidade regular (Amarante, 2004, p.19)

A partir de 1919 passou a ser publicada com o nome de Arquivos Brasileiros de Neuriatria e Psiquiatria. Os diretores justificaram a mudança pelo crescente desenvolvimento dos estudos nessas áreas, como também pelas "determinações do governo, no sentido da máxima economia, impedindo, porém, a impressão nas oficinas do Hospital Nacional" (Nota editorial, 1919). Cabe observar que o uso do termo neuriatria denota o início da separação dos campos da medicina e da psicologia, processo reforçado pela divulgação das teorias psicanalíticas. De acordo com Neves (2008, p.51), iatros é um sufixo relativo a médico, e a neurologia adotou o termo neuriatria para reforçar sua identificação com o campo médico, em especial a psiquiatria. ${ }^{17} \mathrm{~A}$ medicina legal deixou de figurar no título do periódico, ainda que ele tenha continuado a veicular trabalhos nessa área. Também em 1919 foi autorizada a construção do Manicômio Judiciário, instituição que viria a produzir os Arquivos do Manicômio Judiciário do Rio de Janeiro a partir de 1930, publicados semestralmente até a década de $1960 .{ }^{18}$ Segundo Juliano Moreira, tratava-se da primeira publicação especializada nesse segmento específico da psiquiatria.

Enfrentando dificuldades como encarecimento do papel e falta de recursos (Almeida, 1919, p.187), os Arquivos Brasileiros de Neuriatria e Psiquiatria ficaram sob a responsabilidade financeira dos médicos Juliano Moreira, Antonio Austregésilo, Ulysses Vianna, Faustino Esposel, Heitor Carrilho ${ }^{19} \mathrm{e}$ Waldemar de Almeida ${ }^{20}$. Apesar da mudança de nome, continuou a ser o órgão oficial da Sociedade Brasileira de Neurologia, Psiquiatria e Medicina Legal e manteve a publicação de atas e boletins dessa entidade. Após anos sendo custeada pelas assinaturas e por verba do Ministério da Justiça e Negócios Interiores (MJNI), a revista passou a ser sustentada pela Sociedade, que ficou responsável por "metade dos recursos", usando, para isso, as mensalidades dos sócios efetivos (ABNP, 1919, p.187). 
De 1919 a 1930 foi impressa em seis gráfias diferentes: a Besnard Frères em 1919; em 1920, a do Jornal do Commercio, de Rodrigues \& C.; a partir de 1923, a tipografia do Sanatório Botafogo; a dos editores Paulo de Azevedo \& Cia., da Livraria Francisco Alves, assumiu a impressão em 1926; a dos Arquivos Brasileiros de Medicina, em 1929; e por último a do laboratório do Largo da Carioca, em 1930 (ABNP, 1919, 1920, 1923, 1926, 1929).

As propagandas, a princípio inexistentes, tornaram-se frequentes de $1919 \mathrm{em}$ diante. Em geral, diziam respeito a laboratórios, drogarias e fármacos. O laboratório Granado \& Cia. promovia o Camphydral como cânfora natural, e a Bayer anunciava o Luminal, sedativo e antiepilético. Outro produto divulgado foi o Cyanurol, para tratamento da sífilis, preparado pelo Laboratório de Biologia Clínica, que ficava no Largo da Carioca. Em meio a anúncios dessa natureza encontram-se produtos como os refrigerantes da Companhia Cervejaria Brahma, "preparados de acordo com os mais rigorosos princípios higiênicos" (ABNP, 1928).

O Sanatório Botafogo, inaugurado em 31 de Julho de 1921, também aparece nas propagandas devido a seu envolvimento com a redação e administração da revista. Vale lembrar que Ulysses Vianna, um dos diretores dos Arquivos Brasileiros e docente de Clínica Neurológica e Psiquiátrica da Faculdade de Medicina do Rio de Janeiro, era diretor daquele sanatório, junto com Adauto Botelho ${ }^{21}$ e Pedro Pernambuco Filho ${ }^{22}$, assistentes de clínica psiquiátrica do Hospício Nacional. Ignácio Cunha Lopes, assistente do Hospital Nacional, era também médico do Sanatório (ABNP, 1923).

Em virtude da sua abrangência e duração, durante cinco décadas Arquivos Brasileiros circulou pelas mais importantes instituições da antiga capital, o que permite que hoje se tenha acesso a seus números em vários acervos do Rio de Janeiro e de outros estados. As instituições utilizadas para a nossa pesquisa foram a Biblioteca de Manguinhos (Fiocruz), o Instituto de Psicologia (Ipub) e o Centro de Ciência e Saúde, ambos da Universidade Federal do Rio de Janeiro (UFRJ), a Academia Nacional de Medicina e a Biblioteca Nacional.

\section{Conteúdo}

A revista contou com número crescente de colaboradores, oriundos principalmente do Rio de Janeiro e da Bahia, mas também do Rio Grande do Sul e de São Paulo. Exemplos dignos de nota são Nina Rodrigues (Bahia), Francisco Franco da Rocha (São Paulo), e Antonio Carlos Penafiel (Porto Alegre) ${ }^{23}$. Autores estrangeiros também ali publicaram, como o doutor Domingo Felipe Cabred (1859-1929), diretor do Hospicio de las Mercedes e da Colonia Nacional de Alienados de Buenos Aires (ABPNML, 1909, n.3-4).

A revista compreendia as seguintes seções: Artigos $^{24}$ (publicada entre 1905 e 1919) ou Trabalhos Originais (1920 a 1930); Análises (1906-1907, 1919-1920, 1924; 1926-1930); Bibliografia (1905-1909; 1911-1916; 1919-1920, 1924, 1926-1930); Revista das Revistas (19081909, 1912-1913, 1920, 1924); Notas de Terapêutica (1906-1907, 1909 - neste último ano, com o nome de Notas de Fisioterapia); Necrologias (1905-1909, 1918); Notícias (1905, 1908, 1912, 1920, 1924-1930); e ainda Congressos (1906-1907, 1908, 1915-1916), Correspondência (1905-1906) e Versas (1905-1909).

Houve poucas variações nessas seções. Desapareceram algumas, como Versas; mudaram de nome outras. Bibliografia, Análises e Revista das Revistas destinavam-se a resenhas feitas 
por um ou mais colaboradores, inclusive de artigos publicados em revistas internacionais. Os editores versavam sobre obras privilegiando, em geral, aquelas da psiquiatria organicista e da neurologia. Notícias era seção dedicada à divulgação de eventos nacionais e internacionais, em sua maioria congressos de medicina, psiquiatria e de assistência a alienados. Notas de Terapêutica apresentava didaticamente formas de tratamento, medicação e higiene para diferentes moléstias mentais; servia também à discussão de novos diagnósticos, classificações e procedimentos a elas concernentes. Versas publicava poemas de pacientes do Hospício Nacional, variando os temas dos românticos à exaltação patriótica da nacionalidade. $\mathrm{O}$ texto vinha sempre com o diagnóstico do paciente-escritor.

\section{Seleção de fontes}

O exame das matérias publicadas nos Arquivos Brasileiros teve como objetivo inicial obter informações acerca de idéias e práticas em vigor no Hospício Nacional. Assim, o primeiro critério de seleção foi a autoria dos artigos, destacando-se aqueles elaborados por psiquiatras da instituição. Em seguida arrolamos os artigos referentes à Assistência a Alienados no Brasil, aos diagnósticos mais recorrentes na instituição durante o período estudado e às práticas terapêuticas (escassas em nossos documentos clínicos). O número de matérias selecionadas, entre as publicadas ao longo de três décadas, foi tão grande (707) que optamos por registrar esse acervo em banco de dados (base de periódicos), de maneira a permitir diferentes tipos de pesquisa sobre o tema.

Os artigos que aqui reproduzimos foram selecionados entre aqueles publicados de 1905 a 1930, ano da aposentadoria de Moreira, de maneira a revelar os esforços feitos pelo grupo por ele liderado para divulgar a psiquiatria organicista alemã e para disputar, com psiquiatras de outras correntes, a hegemonia teórica e clínica no campo. Nessa seleção, procuramos entrecruzar o interesse por uma história dos sintomas, das doutrinas e das teorias psiquiátricas com o contexto sociopolítico, cultural e profissional do período (Huertas, 2001). Nossa proposta, então, é pensar a psiquiatria como racionalidade científica submetida a fatores socioculturais de seu tempo e lugar, recebida e reelaborada ativamente pelos agentes que dela se apropriam. Em decorrência dessa escolha, as matérias de Arquivos Brasileiros aqui publicadas são, em grande maioria, de médicos do Hospício Nacional e tratam de diagnósticos importantes para o período. Além daqueles diagnósticos que praticamente desapareceram ao longo dos anos estudados (como a histeria ou a neurastenia, advindos do alienismo francês), destacamos os novos, que foram surgindo paulatinamente até ganhar hegemonia na década de 1920 (a exemplo da loucura maníaco-depressiva e da demência precoce). O leitor poderá, assim, observar o processo de mudança na psiquiatria do período e a crescente influência da corrente organicista, especialmente a partir de 1927, quando o Serviço de Assistência a Psicopatas deixou de circunscrever apenas o Distrito Federal e passou a abarcar todo o país. 


\section{NOTAS}

${ }^{1}$ Juliano Moreira (1873-1933), médico baiano, graduou-se na Faculdade de Medicina da Bahia com a tese Sífilis maligna precoce. Em 26 de março de 1903, assumiu a direção do Hospício Nacional de Alienados, acumulando também o cargo de diretor geral da Assistência a Alienados, a convite do ministro dos Negócios Interiores J.J. Seabra, função que exerceu durante 27 anos. Ao se tratar de tuberculose na Alemanha, entrou em contato com a psiquiatria organicista alemã, trazendo muitas dessas teorias para o Brasil, onde difundiu o modelo kraepeliano de psiquiatria (Oda, Dalgalarrondo, 2000).

${ }^{2}$ O baiano Júlio Afrânio Peixoto (1876-1947) mudou-se em 1902 para o Rio de Janeiro, onde foi inspetor de Saúde Pública (1902) e médico do Hospital Nacional de Alienados (1903). Após concurso, foi nomeado professor de Medicina Legal da Faculdade de Medicina do Rio de Janeiro (1907) e assumiu os cargos de professor extraordinário da Faculdade de Medicina (1911), diretor da Escola Normal do Rio de Janeiro (1915), diretor da Instrução Pública do Distrito Federal (1916), deputado federal pela Bahia (1924-1930), professor de História da Educação do Instituto de Educação do Rio de Janeiro (1932) e reitor da Universidade do Distrito Federal (1935). Afrânio Peixoto foi também crítico, ensaísta, romancista e historiador literário (ABL, s.d.).

${ }^{3}$ Francisco Franco da Rocha (1864-1933), paulista, formou-se pela Faculdade de Medicina do Rio de Janeiro, tendo sido aluno de João Carlos Teixeira Brandão (1854-1921), adepto da psiquiatria francesa. Em 1893 ingressou no corpo médico do Hospício de Alienados de São Paulo. Posteriormente foi um dos responsáveis pela inauguração do Hospício de Juqueri, que dirigiu até 1923 (Almeida, 2008).

${ }^{4}$ Antônio Austregésilo Rodrigues Lima (1876-1960) formou-se em 1899 na Faculdade de Medicina do Rio de Janeiro. Entre 1901 e 1909 foi professor substituto de Clínica Médica, Patologia Interna e Clínica Propedêutica. Em 1912 tornou-se catedrático da recém fundada cadeira de Neurologia (Teive et al, 1999).

${ }^{5}$ Raimundo Nina Rodrigues (1862-1906) formou-se em medicina na Bahia. Em 1891 tornou-se professor de Medicina Legal na Faculdade de Medicina da Bahia, depois na de Recife. Foi membro da Academia Nacional de Medicina, da Academia Pernambucana de Letras e do Conselho Nacional de Ensino (19261927). Fundou a Revista Médico-legal. Foi redator da Gazeta Médica da Bahia e assíduo colaborador dos periódicos Brasil-Médico e Revista Médica de São Paulo (Raimundo Nina Rodrigues, s.d.).

${ }^{6}$ Seção de laborterapia do Hospício Nacional, com oficinas nas quais os internos exerciam atividades consideradas terapêuticas: mecânica elétrica, carpintaria e marcenaria, tipografia e encadernação, sapataria, colchoaria e pintura. Foi o primeiro núcleo de trabalho metódico para as seções de homens. Em 1903 foi criada uma oficina de costura na seção de mulheres (Peixoto, 1905, Anexo E).

${ }^{7}$ A instituição foi chamada de Hospício de Pedro II durante o Império; com a proclamação da República, passou a denominar-se Hospício Nacional de Alienados e, em 1911, ganhou o nome de Hospital Nacional de Alienados. Em 1927 foi renomeada como Hospital Nacional de Psicopatas. Neste artigo, será denominada Hospício Nacional.

${ }^{8}$ Henrique de Brito Belford Roxo (1877-1969) formou-se doutor pela Faculdade de Medicina do Rio de Janeiro em 1900, sob orientação de João Carlos Teixeira Brandão (1854-1921). De 1901 a 1910 trabalhou como assistente no Pavilhão de Observação (Roxo, 1910), depois foi diretor dele, mesmo após 1938, quando passou a se chamar Instituto de Psiquiatria (Ipub) da UFRJ (Facchinetti, Venancio, 2006).

${ }^{9}$ Antônio Fernandes Figueira (1863-1928) foi membro titular da Academia Nacional de Medicina (1903). A convite de Oswaldo Cruz dirigiu a enfermaria de doenças infecciosas do Hospital São Sebastião. Também em 1903 foi contratado pelo Hospício Nacional como médico responsável pelo atendimento às crianças do Pavilhão Bourneville (Figueira, 1915).

${ }^{10}$ Ulysses Vianna foi docente de Neurologia Psiquiátrica na Faculdade de Medicina do Rio de Janeiro e alienista da Assistência a Alienados do Distrito Federal. Em 1920 fez estudos de aperfeiçoamento com Alzheimer, em Munique. Mais tarde fundou o Sanatório Botafogo, em sociedade com Pedro Pernambuco e Adauto Botelho (Vianna, 1920).

${ }^{11}$ Faustino Monteiro Esposel (1888-1931) formou-se em 1910 pela Faculdade de Medicina do Rio de Janeiro. Foi livre-docente e assistente de Clínica de Doenças Nervosas na mesma faculdade. Foi ainda chefe de serviço na Policlínica de Botafogo e no Sanatório de Botafogo, médico do Hospício Nacional, adjunto do Hospital da Misericórdia e professor substituto de Medicina Pública na Faculdade de Direito Teixeira de Freitas (Esposel, Lopes, 1914).

${ }^{12}$ Joaquim Moreira da Fonseca (1886-1970) formou-se em 1910 pela Faculdade de Medicina do Rio de Janeiro. Foi assistente de Miguel Couto na cadeira de Clínica Médica, tornando-se livre-docente em 1913. 
Foi membro da Sociedade de Neurologia, Psiquiatria e Medicina Legal do Rio de Janeiro e um dos fundadores da Liga Brasileira de Higiene Mental (Fonseca, 1915).

${ }^{13}$ Waldemar Schiller (1880-1940) assumiu, em parceria com o médico Carlos Eiras, o cargo de diretor da Casa de Saúde Dr. Carlos Eiras em 1909, permanecendo nessa função até o ano de sua morte (História da Casa de Saúde..., s.d.).

${ }^{14}$ Diógenes Sampaio formou-se pela Faculdade de Medicina da Bahia em 1906 e tornou-se médico legista da polícia no ano seguinte. Ingressou na Faculdade de Medicina do Rio de Janeiro em 1911, como professor da cadeira de Química (Santos, Faria, 2006).

${ }^{15}$ Jacinto de Barros foi docente da Faculdade de Medicina do Rio de Janeiro e em 1912 tornou-se médico legista da polícia do Distrito Federal (Barros, 1912).

${ }^{16}$ Miguel Salles era médico legista da Polícia do Distrito Federal.

${ }^{17}$ No período, os termos neurologia, neuriatria, neuropatologia e moléstias nervosas foram utilizados alternativamente (Neves, 2008, p.51). A intenção inicial dos editores era manter duas revistas, o Archivos Brasileiros de Psiquiatria, Neurologia e Medicina Legal e o novo Arquivos Brasileiros de Neuriatria e Psiquiatria. A primeira circularia "sem a obrigatoriedade do ritmo trimestral, pois as determinações governamentais lho impedem, além da circunstância de que a tipografia do Hospital, servida por doentes, sob a direção de apenas um tipógrafo, não poderia, nas condições atuais, manter aquele ritmo" (Nota Editorial, 1919). Mas cortes orçamentários ocorridos no período inviabilizaram esse projeto.

${ }^{18}$ A partir de 1954, quando faleceu Heitor Carrilho, o periódico passou a se chamar Arquivos do Manicômio Judiciário Heitor Carrilho (Amarante, 2004, p.19).

${ }^{19}$ Heitor Pereira Carrilho (1890-1954) ocupou o cargo de diretor do Manicômio Judiciário do Rio de Janeiro desde a fundação, em 1921, até a sua morte. Foi professor catedrático de Clínica Psiquiátrica na Faculdade Fluminense de Medicina e presidente geral e membro do Conselho Penitenciário (Fry, 1985).

${ }^{20}$ Waldemar Gualberto de Almeida, médico psiquiatra e sociólogo. Em 1914 era assistente interino do Hospício Nacional (Almeida, 1919).

${ }^{21}$ Adauto Botelho (1895-1963) foi docente da Faculdade Nacional de Medicina, catedrático da Faculdade de Ciências Médicas do Distrito Federal e um dos fundadores do Sanatório Botafogo. Na gestão Henrique Roxo como diretor do Pavilhão de Observação, foi assistente, chefe de laboratório, chefe de clínica da cátedra e substituto eventual do catedrático. Entre 1937 e 1945 foi diretor do Serviço Nacional de Doenças Mentais (Piccinini, 2009).

22 Pedro Pernambuco Filho foi assistente de psiquiatria e livre-docente da Faculdade de Medicina e médico escolar (Pernambuco Filho, 1927).

${ }^{23}$ Antônio Carlos Penafiel (1883-1960) formou-se médico em 1904 pela Faculdade de Medicina do Rio de Janeiro. Foi membro titular do Conselho Executivo e da Seção de Serviços Sociais e Legislação da Liga Brasileira de Higiene Mental, e catedrático de Fisiologia da Faculdade de Medicina de Porto Alegre (Carvalho, 1999).

${ }^{24}$ Esta denominação não é literalmente usada nos sumários, mas a utilizamos para designar a seção destinada aos artigos principais.

\section{REFERÊNCIAS}

ABL.

Academia Brasileira de Letras. Afrânio Peixoto. Disponível em: http://www.academia.org.br/ abl/cgi/cgilua.exe/sys/start.htm?infoid $=44 \&$ sid=127. Acesso em: 11 jul. 2010. s.d.

ABNP.

Archivos Brasileiros de Neuriatria e Psychiatria. Rio de Janeiro: Sociedade Brasileira de Neurologia, Psiquiatria e Medicina Legal. 1919, 1920, 1923, 1926, 1928, 1929.
ABPNML.

Archivos Brasileiros de Psychiatria, Neurologia e Medicina Legal. Rio de Janeiro, n.3-4. 1909.

ALMEIDA, Francis Moraes de.

O esboço de psiquiatria forense de Franco da Rocha. Revista Latinoamericana de Psicopatologia Fundamental, São Paulo, v.11, n.1, p.137-150. 2008.

ALMEIDA, Waldemar de. Boletim da Sociedade Brasileira de Neurologia, 
Psiquiatria e Medicina Legal. Archivos Brasileiros de Neuriatria e Psychiatria, Rio de Janeiro, 2.trim., p.187-189. 1919.

AMARANTE, Paulo (Ed).

Guia de fontes e catálogo de acervos e instituições para pesquisas em saúde mental e assistência psiquiátrica no estado do Rio de Janeiro. Rio de Janeiro: Laps/Ensp/Fundação Oswaldo Cruz. Disponível em: http:// www4.ensp.fiocruz.br/eventos_novo/dados/ arq423.pdf. Acesso em: 23 jun. 2010. 2004.

AUSTREGÉSILO, Antonio.

Resenha de 'A paranóia (segundo Kraepelin)', tese de Ulysses Vianna Filho, Bahia, 1904.

Archivos Brasileiros de Psychiatria, Neurologia e Sciências Affins, Rio de Janeiro, n.1, p.134-135. 1905.

BARROS, Jacinto de.

Um caso interessante de pseudologia fantástica. Archivos Brasileiros de Psychiatria, Neurologia e Medicina Legal, Rio de Janeiro, n.3-4, p.351-369. 1912.

BRASIL.

Ministério da Justiça e Negócios Interiores. Relatório apresentado ao presidente da República dos Estados Unidos do Brasil pelo dr. Rivadavia da Cunha Corrêa. Rio de Janeiro: Imprensa Nacional. 1912.

CARVALHO, Alexandre Magno Teixeira de. Trabalho e higiene mental: processo de produção discursiva do campo no Brasil. História, Ciências, Saúde - Manguinhos, Rio de Janeiro, v.6, n.1, p.133-156. 1999.

ESPOSEL, Faustino; LOPES, Ernani.

Uma perícia médico-legal: estado degenerativo, alcoolismo crônico. Archivos Brasileiros de Psychiatria, Neurologia e Medicina Legal, Rio de Janeiro, 1914, n.3-4, p.190-240. 1914.

FACCHINETTI, Cristiana; VENANCIO, Ana Teresa A.

Entre a psicanálise e a degenerescência: sexualidade e doença mental no início do século XX no Brasil. Revista Latinoamericana de Psicopatologia Fundamental, São Paulo, ano 9, n.1, p.151-161. 2006.

FIGUEIRA, Antonio Fernandes. Síndrome cefaloplégica em crianças. Archivos Brasileiros de Psychiatria, Neurologia e Medicina Legal, 1915, n.2, p.153-171. 1915.

FONSECA, Joaquim Moreira da. Subsídio ao estudo das formas nervosas do impaludismo. Archivos Brasileiros de Psychiatria, Neurologia e Medicina Legal, Rio de Janeiro, 1915, n.6, p.367-430. 1915.
FRY, Peter.

Direito positivo versus direito clássico: a psicologização do crime no Brasil. In: Figueira, , S. (Org.). Cultura da psicanálise. São Paulo: Brasiliense. p.116-141. 1985.

HISTÓRIA DA CASA DE SAÚDE..

História da Casa de Saúde Dr. Eiras. Disponível em: http://ww.hmattos.kit.net/historiadacasa desaude.html. Acesso em: 6 ago. 2010. s.d.

HUERTAS, Rafael.

Historia de la psiquiatría, ¿por qué?, ¿para qué?: tradiciones historiográficas y nuevas tendencias. Frenia - Revista de Historia de la Psiquiatría, Madrid, v.1, n.1, p.9-36. Disponível em: http://www.frenia-historiapsiquiatria.com/ pdf/fasciculo\%201/009-historia-de-lapsiquiatria-por-que-para-que.pdf. Acesso em: 16 nov. 2010. 2001.

MOREIRA, Juliano.

Querelantes e pseudo-querelantes. Archivos Brasileiros de Psychiatria, Neurologia e Medicina Legal, Rio de Janeiro, n.3-4, p.426-433. 1908.

MOREIRA, Juliano; PEIXOTO, Afrânio. A paranóia e as síndromes paranóides. Archivos Brasileiros de Psychiatria e Sciencias Affins, Rio de Janeiro, n.1, p.5-33. 1905a.

MOREIRA, Juliano; PEIXOTO, Afrânio. Classificação das moléstias mentais do Prof. Emil Kraepelin (1). Archivos Brasileiros de Psychiatria e Sciencias Affins, Rio de Janeiro, n.2, p.204-216. 1905b.

NEVES, Afonso Carlos.

O emergir do corpo neurológico no corpo paulista: neurologia, psiquiatria e psicologia a partir dos periódicos médicos paulistas (1889-1936). Tese (Doutorado) - Programa de Pós-graduação em História Social, Universidade de São Paulo, São Paulo. 2008.

NOTA EDITORIAL.

Archivos Brasileiros de Neuriatria e Psychiatria, Rio de Janeiro, 1.trim., n.p. 1919.

NOTA EDITORIAL.

Archivos Brasileiros de Psychiatria, Neurologia e Medicina Legal, Rio de Janeiro, n.1, n.p. 1915.

NOTA EDITORIAL.

Archivos Brasileiros de Psychiatria e Sciencias Affins, Rio de Janeiro, n.1, n.p. 1905.

ODA, Ana Maria Galdini Raimundo; DALGALARRONDO, Paulo.

Juliano Moreira: um psiquiatra negro frente ao racismo científico. Revista Brasileira de Psiquiatria, São Paulo, v.22, n.4, p.178-179. 2000. 
PEIXOTO, Afrânio.

Hospício Nacional de Alienados. Archivos Brasileiros de Psychiatria e Sciencias Affins, Rio de Janeiro, n.1, p.106-120. 1905.

PERNAMBUCO FILHO.

O problema da educação dos anormais. Archivos Brasileiros de Neuriatria e Psychiatria, 1927, 1.-3.trim., p.91-112. 1927.

PICCININI, Walmor J.

Adauto Junqueira Botelho: notas biográficas. Psychiatry on line Brazil, v.14, n.2. Disponível em: http://www.polbr.med.br/ano09/ wal0209.php. Acesso em: 6 ago. 2010. 2009.

\section{RAIMUNDO NINA RODRIGUES.}

Dicionário Biográfico da Psiquiatria no Brasil. Disponível em: http://bvsms-Bancos.saude. bvs.br/cgi-bin/wxis.exe/iah/psi/. Acesso em: 6 ago. 2010. s.d.

ROCHA, Franco da.

Sobre a psicose maníaco-depressiva. Archivos Brasileiros de Psychiatria e Sciencias Affins, Rio de Janeiro, n.3-4, p.279-288. 1905.

ROXO, Henrique de Brito Belford.

Causas de reinternação de alienados no Hospício Nacional. Archivos Brasileiros de Psychiatria, Neurologia e Medicina Legal, Rio de Janeiro, 1910, n.3-4, p.403-415. 1910.
SANTOS, Luiz Antônio de Castro; FARIA, Lina. O ensino da saúde pública no Brasil: os primeiros tempos no Rio de Janeiro. Trabalho, Educação e Saúde, Rio de Janeiro, v.4, n.2, p.291-324. Disponível em: http://www.ims. uerj.br/downloads/trabalho_educacao saude_texto_castro_santos_e_faria.pdf. Acesso em: 24 ago. 2010. 2006.

SOCIEDADE BRASILEIRA...

Sociedade Brasileira de Psiquiatria, Neurologia e Medicina Legal. Archivos Brasileiros de Psychiatria e Sciencias Affins, Rio de Janeiro, 'n.3-4, p.435-436. 1907.

TEIVE, Hélio A.G. et al. Professor Antonio Austregésilo: o pioneiro da neurologia e do estudo dos distúrbios do movimento no Brasil. Arquivos de NeuroPsiquiatria, São Paulo, v.57, n.3B, p.898-902. Disponível em: http://www.scielo.br/ scielo.php?script=sci_arttext\&pid=S0004282X1999000500030. Acesso em: 4 ago. 2010. 1999.

VIANNA, Ulysses.

A doença de Alzheimer. Archivos Brasileiros de Neuriatria e Psychiatria, Rio de Janeiro, 1920, 1.trim., p.263-282. 1920.

\section{$\rightarrow \rightarrow \rightarrow<<<$}

